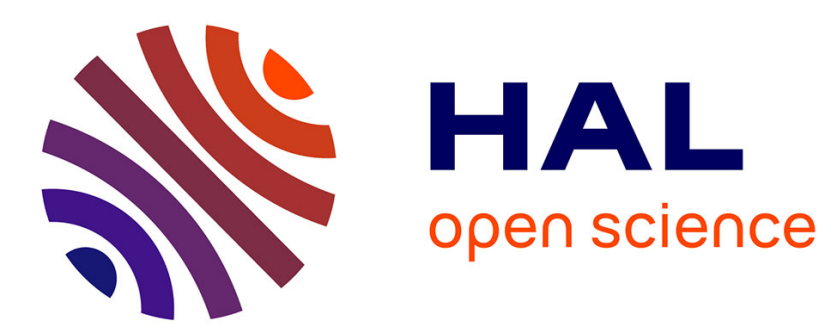

\title{
Magnetic and Optical Studies of Structure of Co-Doped Bismuth-Iron-Garnet
}

\author{
T. Okuda, N. Adachi, H. Ohsato, Y. Katoh, T. Mima
}

\section{To cite this version:}

T. Okuda, N. Adachi, H. Ohsato, Y. Katoh, T. Mima. Magnetic and Optical Studies of Structure of Co-Doped Bismuth-Iron-Garnet. Journal de Physique IV Proceedings, 1997, 07 (C1), pp.C1-711-C1712. 10.1051/jp4:19971289 . jpa-00255003

\section{HAL Id: jpa-00255003 https://hal.science/jpa-00255003}

Submitted on 1 Jan 1997

HAL is a multi-disciplinary open access archive for the deposit and dissemination of scientific research documents, whether they are published or not. The documents may come from teaching and research institutions in France or abroad, or from public or private research centers.
L'archive ouverte pluridisciplinaire HAL, est destinée au dépôt et à la diffusion de documents scientifiques de niveau recherche, publiés ou non, émanant des établissements d'enseignement et de recherche français ou étrangers, des laboratoires publics ou privés. 


\title{
Magnetic and Optical Studies of Structure of Co-Doped Bismuth-Iron- Garnet
}

\author{
T. Okuda, N. Adachi, H. Ohsato, Y. Katoh and T. Mima \\ Section of Inorganic Materials, Department of Materials Science and Engineering, Nagoya Institute of \\ Technology, Gokiso-cho, Showa-ku, Nagoya, 466, Japan
}

\begin{abstract}
Using an alternating reactive ion beam sputtering technique, Co ion was doped in epitaxially growing $\mathrm{Bi}_{3} \mathrm{Fe}_{5} \mathrm{O}_{12}$ garnet film. The intense enhancement of magnetization, coercivity, and optical absorption at $633 \mathrm{~nm}$ was observed. The Faraday hysteresis loop for slightly Co-doped film showed anomalous behavior. Those phenomena can be understood considering the composite film structure in which fine particles of $\mathrm{Co}_{3-x} \mathrm{Fe}_{x} \mathrm{O}_{4}$ spinel are embedded in epitaxially grown $\mathrm{Bi}_{3} \mathrm{Fe}_{5} \mathrm{O}_{12}$.
\end{abstract}

\section{INTRODUCTION}

$\mathrm{Bi}_{3} \mathrm{Fe}_{5} \mathrm{O}_{12}$ (BIG) is a magnetically soft ferrimagnet with garnet structure. For near infrared light, BIG is transparent and shows giant Faraday rotation $\left(\theta_{\mathrm{F}}\right)[1,2]$. It is well known that, in magnetic oxides, $\mathrm{Co}^{2+}$ ion occupies octahedral $(O)$ site contributing large magnetocrystalline anisotropy which results in high coercivity and that tetrahedral $(T)$ site $\mathrm{Co}^{2+}$ strongly induces optical absorption and Faraday rotation due to crystal field transition $\left({ }^{4} A_{2} \rightarrow{ }^{4} T_{1}\right)$ at around the wavelengths of 0.7 and $1.5 \mu \mathrm{m}$. These modification effects due to $\mathrm{Co}^{2+}$ ion are also expected in $\mathrm{BIG}$, which are worth investigating from both viewpoints of fundamental research and application of BIG. On the Co-doped BIG films prepared by reactive alternating ion beam sputtering, we have reported the enhancement of magnetization and coercivity and the different values of coercivity derived from the $\theta_{\mathrm{F}}$ hysteresis loops measured at different wavelengths, $633 \mathrm{~nm}$ and $1.5 \mu \mathrm{m}[3]$. The results of further investigation will be described.

\section{EXPERIMENTAL}

The films were deposited onto the (111) oriented $\mathrm{Gd}_{3}(\mathrm{ScGa})_{5} \mathrm{O}_{12}$ gamet substrates kept at $500^{\circ} \mathrm{C}$ in an oxydizing atmosphere by alternatingly sputtering the two ceramic targets $\mathrm{T}_{\mathrm{A}}\left(=\mathrm{BIG}=3 \mathrm{Bi}_{2} \mathrm{O}_{3}-5 \mathrm{Fe}_{2} \mathrm{O}_{3}\right)$ and $\mathrm{T}_{\mathrm{B}}(=\mathrm{CoO})$ using $\mathrm{Ar}$ ion beam[3]. The sputtering time fraction $R_{s T}=t_{A} /\left(t_{A}+t_{B}\right)$ was varied from 0 to $1 . t_{A}$ and $t_{B}$ are sputtering time in one period for respective targets. $t_{A}$ was varied from 0 to $9 \mathrm{~min}$ and $t_{B}$ fixed at $1 \mathrm{~min}$. The total sputtering time of each run was set at 600 min. The films were characterized at room temperature using X-ray diffractometer (XRD), AFM (atomic force microscope), vibrating sample magnetometer (VSM), infrared and visible spectrometer, and Faraday rotation spectrometer.

\section{RESULTS AND DISCUSSION}

In the range of $0<R_{S T}<1$, no indication of periodic layered structure was found in XRD peaks measured at low and high diffraction angle. $\mathrm{BIG} / \mathrm{CoO}$ layered structure will be hardly formed because of bigh substrate temperature. In the range of $0.833<\mathrm{R}_{\mathrm{ST}}<1$, main phase is epitaxially grown garnet phase $(G)$. At $\mathrm{R}_{\mathrm{ST}}=0.833$, (111) oriented spinel phase $(S)$ appears infrequently. In the range of $0 \leqq \mathrm{R}_{\mathrm{sr}} \leqq 0.75, G$-phase, $\mathrm{BiFeO}_{3}$, and $\mathrm{Bi}_{2} \mathrm{Fe}_{4} \mathrm{O}_{9}$ do not appear, but $S$-phase and some unidentified phases are frequently observed. From these facts, we can deduce that, in the range $0 \leqq R_{\mathrm{ST}} \leqq 0.8$, S-phase is the main and $G$-phase does not grow if $\mathrm{R}_{\mathrm{sT}} \leqq 0.75$.

In the range of $0.5 \leqq \mathrm{R} \leqq 1$, the specimens are ferromagnetic at room temperature. As shown in Fig. 1 , $\mathrm{R}_{\mathrm{ST}}$ dependence of the 


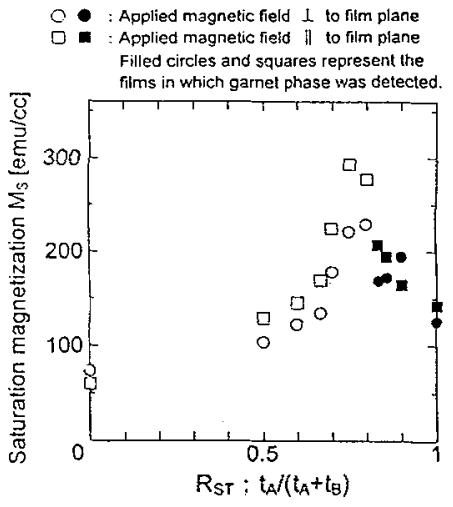

Fig.1 Room temperature saturation magnetization of Co-doped BIG films vs. $\mathrm{R}_{\mathrm{ST}}$.

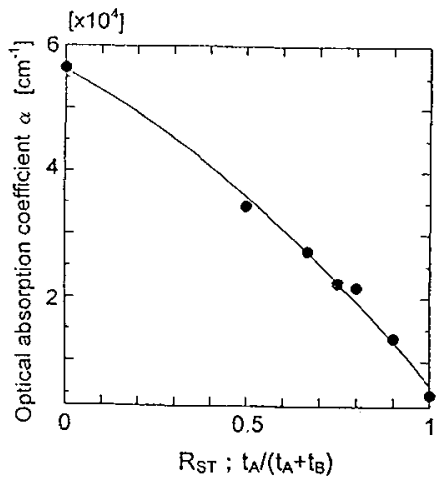

Fig.2 Optical absorption coefficient of Co-doped BIG films at $633 \mathrm{~nm}$ vs. $\mathrm{R}_{\mathrm{ST}}$

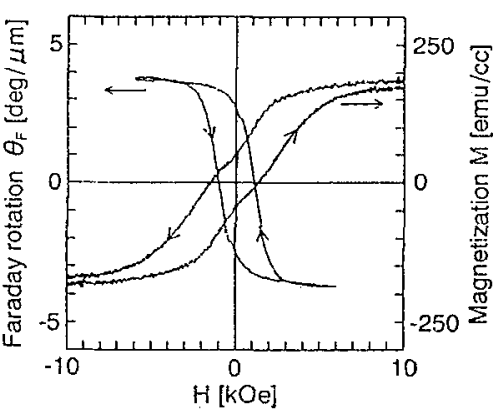

Fig.3 Faraday and magnetization. hysteresis loops of the sample of $R_{\mathrm{ST}}=0.9 . \dot{\theta}_{\mathrm{F}}$ was measured at $633 \mathrm{~nm}$.

saturation magnetization $M_{\mathrm{S}}$ measured at room temperature has a prominent peak at $\mathrm{R}_{\mathrm{ST}} \doteqdot 0.75$ and the peak value of 300 emuicc is about twice of that of BIG. Existence of $G$ - or $S$-phases was not confirmed by means of XRD. The coersivity $H_{\mathrm{C}}$ increases monotonically with decrease of $\mathrm{R}_{\mathrm{ST}}$. At $\mathrm{R}_{\mathrm{ST}}=0.9$ and $0.5, H_{\mathrm{C}}$ are 1 and $1.8 \mathrm{kOe}$, respectively. $\mathrm{R}_{\mathrm{ST}}$ dependence of $M_{\mathrm{S}}$ can not be understood by the substitution of $\mathrm{Co}^{2+}$ for $\mathrm{Fe}^{3+}$ in $G$-phase. It will be natural to consider the formation of ferromagnetic phase with high $M_{\mathrm{s}}$ other than $G$-phase. The most plausible phase is $S_{\mathrm{CF}}$-phase, $\mathrm{Co}_{3 . X} \mathrm{Fe}_{X} \mathrm{O}_{4}$ whose $M_{\mathrm{S}}$ increases monotonically as $x$ which may be proportional to $\mathrm{R}_{\mathrm{ST}}$ increases. The room temperature $M_{\mathrm{S}}$ of $\mathrm{CoFe}_{2} \mathrm{O}_{4}$ is $320 \mathrm{emu} / \mathrm{cc}$. The volume fraction of $S_{\mathrm{CF}}$-phase in a film and Co-content in $S_{\mathrm{CF}}$-phase decrease as $R_{\mathrm{ST}}$ increases, which may explain $\mathrm{R}_{\mathrm{ST}}$ dependence of $M_{S}$.

The crystal structure of either $G$ - and $S$-phases contains $T$ - and $O$-sites. The crystal field transition of $\mathrm{Co}^{2+}$ at the $T$-site, which is allowed one, results in optical absorptions at wavelengths of $0.6,1.4$ and $2.5 \mu \mathrm{m}$. The absorption measured at $633 \mathrm{~nm}$ shown in Fig.2 decreases monotonically and intensely as $\mathrm{R}_{\mathrm{ST}}$ increases, which suggests that this absorption is caused by Co ${ }^{2+}$ on the $T$-site in $S_{\mathrm{CF}}$-phase, since $\mathrm{Co}^{2+}$ is hardly introduced into $G$-structure. In $S$-structure, $\mathrm{Co}^{2+}$ substitutes preferentially at O-sites, however, small amount of $\mathrm{Co}^{2+}$ at $T$-sites in $S_{\mathrm{CF}}$-phase may cause strong absorption because the transition is allowed.

In a film containing small amount of $\mathrm{Co}^{2+}$, a peculiar behavior of $\theta_{\mathrm{F}}$ hysteresis loop measured at $633 \mathrm{~nm}$ was observed. As shown in Fig.3, the sign of $\theta_{F}$ changes before the applied field decreased from saturation to 0 Oe. The hysteresis loop measured in the same field strength range using VSM shows step-like change. These can be understood by exchange coupling effect between magnetically soft BIG of giant $\theta_{\mathrm{F}}$ and magnetically hard $S_{\mathrm{CF}}$-phase.

\section{CONCLUSION}

Wc can deduce that the films of $\mathrm{R}_{\mathrm{Sl}}=0.9$ are composites in which fine particles of $S_{\mathrm{CF}}$-phase which are hardly detected by XRD because of the small size and volume fraction are embedded in epitaxially grown BIG films.

\section{References}

[1] Okuda T., Koshizuka N., Hayashi K., Satoh K., Taniguchi H., and Yamamoto H., Digests of 11 th Ann.Conf.Magn.Jpn. $2 \mathrm{aC5}$ and $2 \mathrm{aC6}$ (1987); IEEE Trans.J.Magn.Jpn 3(1988)483; Extended Abstract of 12th Int.Colloq Magn. Films and Surfaces(1988)W 1-04.

[2] Okuda T., Katayama T., Kobayashi H., Kobayashi N., Satoh K, and Yamamoto H., J.Appl.Phys.67(1990)4944.

[3] Okuda T., Katoh Y., Ohsato H., Adachi N., Ando K., Abe T., and Yamamoto H., J.Magn.Magn.Mat. 148(1995)275. 